\title{
Idesolide, an Isolate of Idesia polycarpa, Inhibits Apoptosis through Induction of Intracellular Heat Shock Protein 70 in $\mathbf{C}_{2} \mathbf{C}_{12}$ Muscle Cells
}

\author{
Min-Ho Jung, ${ }^{a}$ Jung-Min Yoo, ${ }^{a}$ Yeo-Jin Kang, ${ }^{a}$ Hyoung Woo LeE, ${ }^{b}$ Seung Hyun Kim, ${ }^{b}$ \\ Sang Hyun Sung, ${ }^{c}$ Yong-Jin LeE, ${ }^{d}$ Inho CHOI, ${ }^{a}$ and Tack-Joong KIM ${ }^{*}, a$ \\ ${ }^{a}$ Division of Biological Science and Technology, College of Science and Technology, Institute of Biomaterials, Yonsei \\ University; Wonju 220-710, Korea: ${ }^{b}$ Institute for Life Science, Elcomscience Co., Ltd.; Seoul 152-742, Korea: ${ }^{c}$ College of \\ Pharmacy, Seoul National University; Seoul 151-742, Korea: and ${ }^{d}$ Chuncheon Bioindustry Foundation; Chuncheon \\ 200-161, Korea. Received January 30, 2010; accepted March 5, 2010; published online March 15, 2010
}

\begin{abstract}
Muscle disorders, such as muscular dystrophy, are associated with an increase in oxidative stress. Proposed treatments for muscular dystrophy, some in clinical trials, include gene therapy and muscle cell transplantation. In this study, we investigated the effects of idesolide, isolated from the fruits of Idesia polycarpa, on changes that occur in muscle disuse atrophy. We noted protective effects on oxidative stress response and HSP70 regulation. Pre-treatment with idesolide for $24 \mathrm{~h}$ maintained cell viability and decreased apoptosis in $\mathrm{H}_{2} \mathrm{O}_{2}$-treated $\mathrm{C}_{2} \mathrm{C}_{12}$ muscle cells. The idesolide pretreatment also increased intracellular HSP70 protein. Our results suggest that idesolide inhibits cell death through induction of HSP70 in $\mathrm{C}_{2} \mathrm{C}_{12}$ muscle cells. This work is the first to report that idesolide can regulate the decrease in HSP70 that occurs during skeletal muscle atrophy.
\end{abstract}

Key words idesolide; $\mathrm{C}_{2} \mathrm{C}_{12}$; muscle atrophy; heat shock protein

Skeletal muscle atrophy typically results from reduced muscle use, as in immobilization, unloading, bed rest, denervation, and space flight. ${ }^{1,2)}$ Skeletal muscle is susceptible to injury by reactive oxygen species (ROS) even under physiological conditions because of rapid bursts of electron transport and oxygen flux during contraction. ${ }^{3)}$ Intense exercise may lead to muscle injury by increasing ROS production. ${ }^{4-6)}$ Muscle redox status, especially during atrophy, is more oxidative than redox status in other organs. Muscle stem cells, including exogenous myoblasts reconstituted with proteins, such as dystrophin, are expected to provide effective cell therapies for muscular dystrophy. ${ }^{7,8)}$ However, enhancing antioxidant defenses in the myoblasts or stem cells as they repopulate muscle compartments and assume functional loads, as in exercise and disease, is important.

Heat shock protein (HSP) expression increases in response to stressors, such as ethanol, amino acid analogues, infection, inhibitors of energy metabolism, and heavy metals. ${ }^{9)}$ HSP70 protects cells from a number of apoptotic stimuli, including heat shock, tumor necrosis factor, growth factor withdrawal, oxidative stress, chemotherapeutic agents, ceramide, and radiation. ${ }^{10-14)}$ HSP70 is significantly down-regulated in various models of skeletal muscle atrophy. ${ }^{15-19)} \mathrm{A}$ decrease in HSP70 may, therefore, positively contribute to pathogenic stress responses, such as those that occur during skeletal muscle disuse.

Idesia polycarpa Mахім. is a deciduous tree of the Flacourtiaceae family, indigenous to Asia and well-known in Korea, China, Japan, and Taiwan. In Korea, the seeds have been used as an insecticide, and the leaves are known to have hemostatic activity. ${ }^{20)}$ We recently reported that idesolide, isolated from the fruits of Idesia polycarpa, significantly reduces nitric oxide induction by lipopolysaccharide in BV2 microglial cells. ${ }^{20)}$

Here, we demonstrate that idesolide increases resistance and intracellular $\mathrm{HSP} 70$ level to $\mathrm{H}_{2} \mathrm{O}_{2}$-induced oxidative stress in $\mathrm{C}_{2} \mathrm{C}_{12}$ muscle cells.

* To whom correspondence should be addressed. e-mail: ktj@yonsei.ac.kr

\section{MATERIALS AND METHODS}

Materials Cell culture materials were purchased from Gibco-BRL (Gaithersburg, MD, U.S.A.); the HSP70 and $\beta$ actin antibodies, from Cell Signaling Technology (Danvers, MA, U.S.A.). The idesolide was prepared as described previously. ${ }^{20)}$ All other chemicals used were of the highest analytical grade commercially available.

Cell Culture $\mathrm{C}_{2} \mathrm{C}_{12}$ muscle cells were cultured in Dulbecco's Modified Eagle's Medium (DMEM: SigmaAldrich, St. Louis, MO, U.S.A.) supplemented with $10 \%$ fetal bovine serum (FBS), penicillin $100 \mathrm{U} / \mathrm{ml}$, streptomycin $100 \mu \mathrm{g} / \mathrm{ml}, \quad N$-(2-hydroxyethyl)piperazine- $N^{\prime}$-2-ethanesulfonic acid (HEPES) $8 \mathrm{~mm}$ and L-glutamine $2 \mathrm{~mm}$. Cells were maintained at $37^{\circ} \mathrm{C}$ in a humidified $5 \% \mathrm{CO}_{2}$ incubator.

Cell Viability Cell viability was determined using the EZ-Cytox cell viability kit (Daeil Lab., Seoul, Korea) following the manufacturer's instructions. Initially, the cells were seeded into 96 -well culture plates at $1 \times 10^{4}$ cells $/ \mathrm{ml}$ and cultured in DMEM containing $10 \% \mathrm{FBS}$ at $37^{\circ} \mathrm{C}$. When cells reached $70 \%$ confluence, the medium was replaced with serum-free DMEM containing various concentrations of idesolide for $24 \mathrm{~h}$. These culture media were then replaced with $0.1,0.5,1,2$, or $4 \mathrm{~mm} \mathrm{H}_{2} \mathrm{O}_{2}$. Control cells were cultured in DMEM without $\mathrm{H}_{2} \mathrm{O}_{2}$. EZ-Cytox kit reagents were added to the medium, and the cells were incubated for $1 \mathrm{~h}$. To evaluate the strength of the idesolide effect on the cellular response to stress, $N$-acetyl cysteine (NAC) was included as a reference (positive control). The optical density was determined at $450 \mathrm{~nm}$ using a microplate reader (BioTek Instruments Inc., Winooski, VT, U.S.A.).

Detection of Apoptosis $\mathrm{C}_{2} \mathrm{C}_{12}$ muscle cells $\left(2.5 \times 10^{5}\right.$ cells $/ \mathrm{cm}^{2}$ ) were cultured on a coverglass, fixed in $4 \%$ paraformaldehyde, and membrane-permeabilized by exposure for $30 \mathrm{~min}$ to $0.1 \%$ Triton X-100 in phosphate-buffered saline at room temperature. Cells were then exposed to 4,6diamino-2-phenylindole (DAPI) solution. Apoptotic cells were identified by the morphological changes observed in the 
stained cells by fluorescence microscopy. For each determination, three separate counts of 100 cells were scored. Apoptosis (i.e., the number of cells with apoptotic nuclear morphology) was expressed as a percentage of the total number of cells counted.

Western Blot Analysis $\quad \mathrm{C}_{2} \mathrm{C}_{12}$ muscle cells were cultured for $24 \mathrm{~h}$ with or without idesolide $(25 \mu \mathrm{M})$, then treated with $\mathrm{H}_{2} \mathrm{O}_{2} 1 \mathrm{~mm}$ (by addition to the medium) for $1 \mathrm{~h}$. The cell lysates were analyzed by sodium dodecyl sulfate-polyacrylamide gel electrophoresis (SDS-PAGE) on 7.5-10\% polyacrylamide gels according to the method described by Ahn et $a l .,{ }^{21)}$ and the proteins were transferred to polyvinylidene difluoride (PVDF) membranes (Bio-Rad, Hercules, CA, U.S.A.). The membranes were blocked overnight at $4{ }^{\circ} \mathrm{C}$ in Tris-buffered saline containing $0.1 \%$ Tween 20 (TBS/T) and 5\% skimmed milk powder, and then incubated with $1: 2000$ dilutions of HSP70 and $\beta$-actin antibodies. Blots were washed with $\mathrm{TBS} / \mathrm{T}$ and incubated with a $1: 5000$ dilution of horseradish peroxidase-conjugated anti-rabbit immunoglobulin G (IgG) (Cell Signaling Technology). Proteins were detected using an enhanced chemiluminescence (ECL) detection reagent for Western blots (GE Healthcare, Buckinghamshire, U.K.).

Statistical Analysis Experimental results are expressed as means \pm S.D. One-way analysis of variance (ANOVA) was followed with the Dunnett's test for multiple comparisons. $p$ values $<0.05$ and $<0.01$ were considered statistically significant, as indicated.

\section{RESULTS}

Idesolide Has No Cytotoxic Effect on $\mathbf{C}_{2} \mathbf{C}_{12}$ Cells The structure of idesolide is shown in Fig. 1A. To determine the cytotoxicity of idesolide, we treated $\mathrm{C}_{2} \mathrm{C}_{12}$ cells with idesolide at concentrations from 10 to $100 \mu \mathrm{M}$ for $24 \mathrm{~h}$ and measured cell viability using the EZ-Cytox kit. Within this dose range, idesolide showed no evidence of cytotoxicity in $\mathrm{C}_{2} \mathrm{C}_{12}$

A

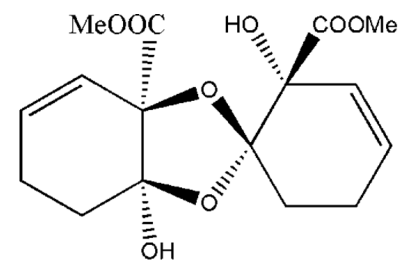

B

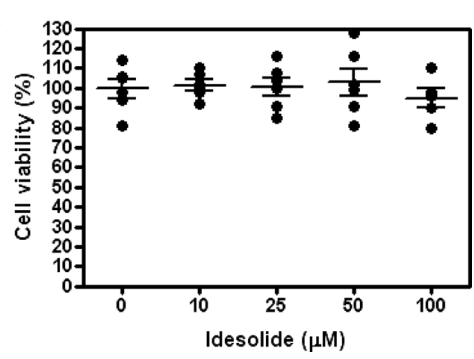

Fig. 1. Chemical Structure and Cytotoxicity of Idesolide, Isolated from the Fruits of Idesia polycarpa

(A) Chemical structure of idesolide. (B) Cytotoxicity of idesolide in $\mathrm{C}_{2} \mathrm{C}_{12}$ muscle cells. Cells were cultured in 96-well plates until confluent, and the medium was replaced with serum-free medium with or without idesolide $(0-100 \mu \mathrm{M})$ for $24 \mathrm{~h}$. The EZ-Cytox reagent was added to the medium, and cells were incubated for $1 \mathrm{~h}$. The optical density was determined at $450 \mathrm{~nm}$ using a microplate reader. Shown are the mean values ( \pm S.D.) from six experiments. muscle cells (Fig. 1B).

Idesolide Protects $\mathrm{C}_{2} \mathrm{C}_{12}$ Muscle Cells against $\mathrm{H}_{2} \mathrm{O}_{2}$-Induced Stress Cell injury associated with ROS may contribute to a variety of muscle diseases and pathologic conditions. ${ }^{22}$ To clarify the effect of idesolide on the oxidative stress response in muscle cells, we exposed $\mathrm{C}_{2} \mathrm{C}_{12}$ cells to $\mathrm{H}_{2} \mathrm{O}_{2}$. In control cultures (not preincubated with idesolide), cell viability decreased following $\mathrm{H}_{2} \mathrm{O}_{2}$ exposure in a dosedependent manner. At $1 \mathrm{~mm}, \mathrm{H}_{2} \mathrm{O}_{2}$ reduced cell viability by almost $72 \%$ (Fig. 2A). In contrast, the idesolide pre-treatment significantly reduced the loss of cell viability at $0.5,1$, 2 , and $4 \mathrm{~mm} \mathrm{H}_{2} \mathrm{O}_{2}$. At a fixed $\mathrm{H}_{2} \mathrm{O}_{2}$ concentration (1 mM), cell viability recovered significantly as the idesolide concentration increased from 1 to $25 \mu \mathrm{M}$ (Fig. 2B). As compared with the antioxidant $N$-acetyl cysteine (NAC) (positive control),

A

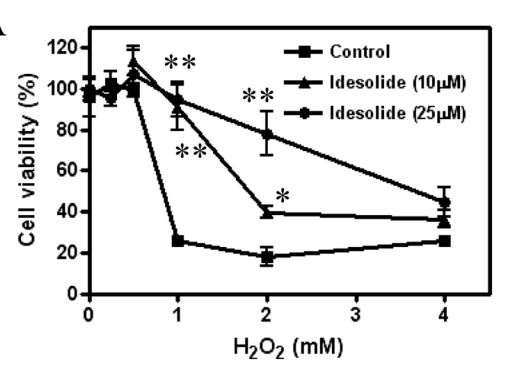

B

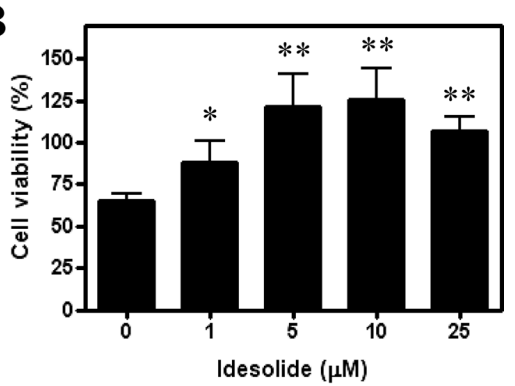

C

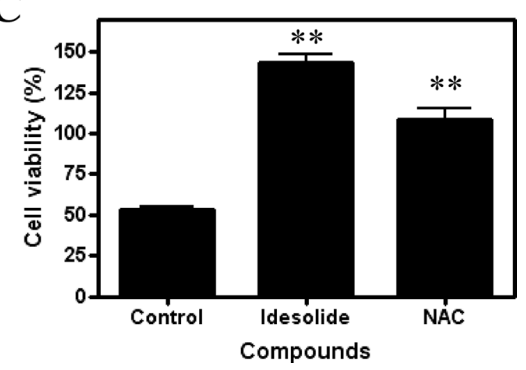

Fig. 2. Antioxidant Effects of Idesolide in $\mathrm{H}_{2} \mathrm{O}_{2}$-Treated $\mathrm{C}_{2} \mathrm{C}_{12}$ Muscle Cells

(A) Dose-dependent effect of $\mathrm{H}_{2} \mathrm{O}_{2}$ on $\mathrm{C}_{2} \mathrm{C}_{12}$ muscle cell viability. Cells were cultured in 96-well plates until confluent and medium was then replaced with serum-free medium with or without idesolide at 10 or $25 \mu \mathrm{M}$. After pre-incubation for $24 \mathrm{~h}$, graded concentrations of $\mathrm{H}_{2} \mathrm{O}_{2}(0-4 \mathrm{~mm}$, as indicated $)$ were added for $1 \mathrm{~h}$. The EZ-Cytox reagent was added to the medium, and the cells were incubated further for $1 \mathrm{~h}$. (B) Concentration-dependent effect of idesolide on $\mathrm{C}_{2} \mathrm{C}_{12}$ muscle cell viability. After pre-incubation with idesolide at the indicated concentrations, $\mathrm{C}_{2} \mathrm{C}_{12}$ cultures were treated with $1 \mathrm{mM} \mathrm{H}_{2} \mathrm{O}_{2}$ for $1 \mathrm{~h}$. EZ-Cytox reagent was added to the medium, and the cells were incubated for $1 \mathrm{~h}$. (C) Comparative effects of idesolide and $\mathrm{N}$-acetyl cysteine (NAC) on viability in $\mathrm{H}_{2} \mathrm{O}_{2}$-treated $\mathrm{C}_{2} \mathrm{C}_{12}$ muscle cells. Cells were cultured in 96-well plates until confluent and the medium was then replaced with serum-free medium with or without idesolide $(25 \mu \mathrm{M})$, NAC $(5 \mathrm{~mm})$ for $24 \mathrm{~h}$. After this pre-incubation, cells were treated with $\mathrm{H}_{2} \mathrm{O}_{2}(1 \mathrm{~mm})$ for $1 \mathrm{~h}$. Optical density was determined at $450 \mathrm{~nm}$ using a microplate reader. The cell viability was calculated by the following equation: cell viability (\%): [(absorbance of $\mathrm{H}_{2} \mathrm{O}_{2}$-treated sample/absorbance of $\mathrm{H}_{2} \mathrm{O}_{2}$-untreated control) $\times 100$ ]. Shown are the mean values $( \pm$ S.D.) from three experiments, each performed in triplicate $(* p<0.05, * * p<0.001)$ 
idesolide showed a greater reduction of $\mathrm{H}_{2} \mathrm{O}_{2}$-induced viability loss in $\mathrm{C}_{2} \mathrm{C}_{12}$ muscle cells (Fig. 2C). Hence, the idesolide pre-treatment clearly modulates the antioxidant defenses of $\mathrm{C}_{2} \mathrm{C}_{12}$ muscle cells. To test the effect of idesolide on apoptotic cell death, we evaluated changes in the chromatin morphology of $\mathrm{H}_{2} \mathrm{O}_{2}$-treated $\mathrm{C}_{2} \mathrm{C}_{12}$ muscle cells using DAPI staining. Treatment with $\mathrm{H}_{2} \mathrm{O}_{2}$ for $1 \mathrm{~h}$ caused apoptosis characterized by chromatin condensation, small membranebound bodies (apoptotic bodies), cytoplasmic condensation, and cell shrinkage. Pre-treatment for $24 \mathrm{~h}$ with idesolide reduced apoptosis in $\mathrm{H}_{2} \mathrm{O}_{2}$-treated $\mathrm{C}_{2} \mathrm{C}_{12}$ muscle cells (Fig. 3).

Idesolide Modulates $\mathrm{HSP70}$ Expression in $\mathrm{H}_{2} \mathrm{O}_{2}-$ Treated $\mathbf{C}_{2} \mathbf{C}_{12}$ Muscle Cells Significant down-regulation of HSP70 in models of muscle atrophy implies that HSP70 activity may protect muscle. ${ }^{15-19)}$ We hypothesized that idesolide protects these cells through modulation of HSP70 signaling in the cellular response to stress. We tested the effects of idesolide on HSP70 expression in $\mathrm{H}_{2} \mathrm{O}_{2}$-treated cells by Western blotting. Following culture for $24 \mathrm{~h}$ in the presence or absence of idesolide $(25 \mu \mathrm{M}), \mathrm{C}_{2} \mathrm{C}_{12}$ muscle cells were treated for $1 \mathrm{~h}$ with $1 \mathrm{mM} \mathrm{H}_{2} \mathrm{O}_{2}$. As shown in Fig. 4, the HSP70 protein increased significantly (9.2-fold) in the idesolide-pretreated cells. This result suggests that idesolide inhibits apoptosis through induction of HSP70 in $\mathrm{C}_{2} \mathrm{C}_{12}$ muscle cells.

\section{DISCUSSION}

In addition to the functional defect in dystrophin, studies show an increase in oxidative stress in muscular dystrophy. ${ }^{23-26)}$ Skeletal muscle cells and myoblasts are susceptible to oxidative stress induced through electron transport and oxygen flux during normal contraction, and this stress may increase with exercise intensity. ${ }^{1-6)}$ Augmentation of cellular antioxidant defense presents a basic strategy to control oxidative muscle injury and related disease conditions. The present study demonstrates the potential benefits of herbal medicines in treating oxidative stress-related muscle disorders. These medicines may potentiate cell therapy regimens now in development for the muscular dystrophies. Our findings suggest that idesolide enhances inherent oxidative stress defenses. In this capacity, it counteracts $\mathrm{H}_{2} \mathrm{O}_{2}$-induced loss of cell viability, dependent on dose (Fig. 2), and decreases $\mathrm{H}_{2} \mathrm{O}_{2}$-induced apoptosis in $\mathrm{C}_{2} \mathrm{C}_{12}$ muscle cells (Fig. 3).

Idesolide may exert its protective effects through modulation of HSP70. In heat shock- or ceramide-induced apoptosis, HSP70 prevents caspase-3 and SAPK/JNK activation. ${ }^{27,28)}$ The cell-protective effects of HSP70 are closely linked to apoptosis inhibition, ${ }^{10-14,27-29)}$ and evidence suggests that HSP70 prevents apoptosis by inhibiting the SAPK/JNK signaling cascade. ${ }^{28,30,31)}$ The aim in this study was, therefore, to identify a step in muscle cell apoptosis at which HSP70 may act. Hence we found that HSP70 protein increased significantly in idesolide-treated $\mathrm{C}_{2} \mathrm{C}_{12}$ muscle cells (Fig. 4).

Although we focused on HSP70 induction in myoblasts and linked its protective function to antioxidant defense, the full role of idesolide in this function awaits further study. Idesolide may participate in other pathways involving antioxidative enzymes and cellular components that generate free radicals. An antioxidant molecule may engage in complex
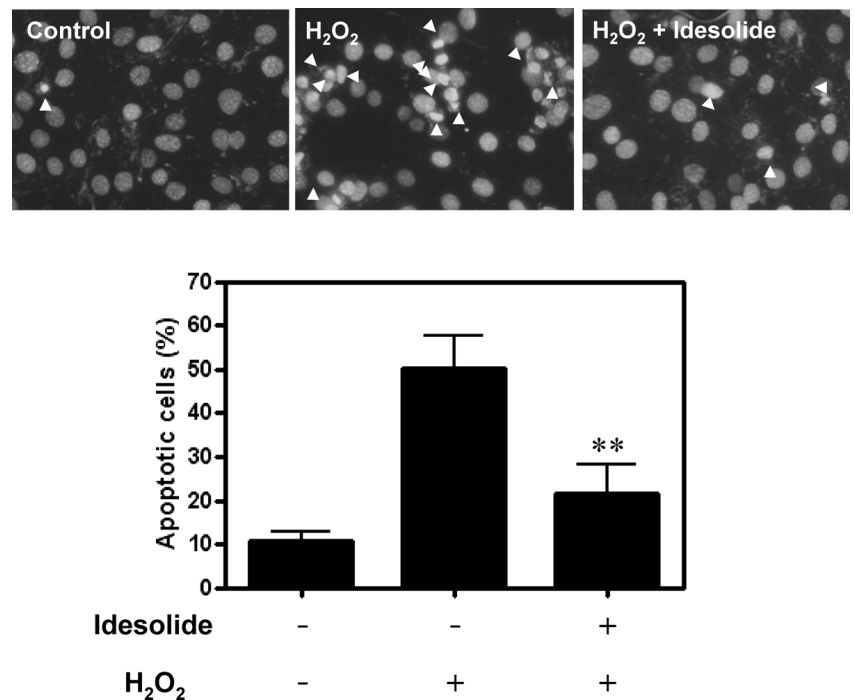

Fig. 3. Effect of Idesolide on $\mathrm{H}_{2} \mathrm{O}_{2}$-Induced Apoptosis in $\mathrm{C}_{2} \mathrm{C}_{12}$ Muscle Cells

$\mathrm{C}_{2} \mathrm{C}_{12}$ muscle cells $\left(2.5 \times 10^{5}\right.$ cells $\left./ \mathrm{cm}^{2}\right)$ were cultured on a coverglass for $24 \mathrm{~h}$ with or without idesolide $(25 \mu \mathrm{M})$, then treated with $1 \mathrm{mM} \mathrm{H}_{2} \mathrm{O}_{2}$ for $1 \mathrm{~h}$. Cells grown on coverglass were stained with DAPI and examined by fluorescence microscopy. Apoptotic cells were estimated by direct counting of fragmented nuclei after staining. The arrows indicate an apoptotic cell. Values represent the means \pm S.D. of three experiments, each performed in triplicate $(* * p<0.001)$.

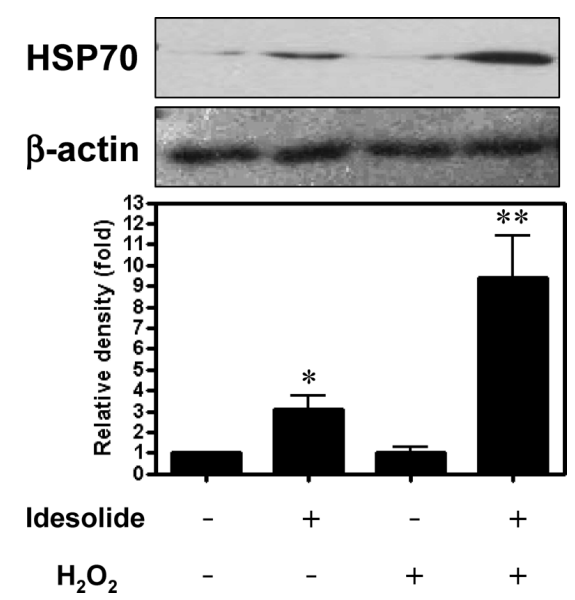

Fig. 4. Effect of Idesolide on HSP70 Levels in $\mathrm{H}_{2} \mathrm{O}_{2}$-Treated $\mathrm{C}_{2} \mathrm{C}_{12}$ Muscle Cells

Cells were cultured in 6-well plates until confluent, and the medium was then replaced with serum-free medium with or without idesolide $(25 \mu \mathrm{M})$ for $24 \mathrm{~h}$. Cells were treated with $1 \mathrm{mM} \mathrm{H}_{2} \mathrm{O}_{2}$ for $1 \mathrm{~h}$ and lysed, and proteins in the lysates were analyzed by SDS-PAGE. Band intensities were quantified by densitometry. Shown are the mean values $( \pm$ S.D. $)$ of $\mathrm{HSP} 70 / \beta$-actin from three independent experiments, each performed in triplicate $(* p<0.05, * * p<0.001)$

signal transduction reactions in a stress response.

In conclusion, we have shown that idesolide increases resistance and intracellular $\mathrm{HSP} 70$ to $\mathrm{H}_{2} \mathrm{O}_{2}$-induced oxidative stress in $\mathrm{C}_{2} \mathrm{C}_{12}$ muscle cells. Through its ability to induce HSP70, idesolide treatment may delay or prevent skeletal muscle atrophy.

Acknowledgments This research was supported by the National Space Lab (NSL) program, through the National Research Foundation of Korea, funded by the Ministry of Education, Science and Technology (Grant No. 2008-03190). 


\section{REFERENCES}

1) Thomason D. B., Biggs R. B., Booth F. W., Am. J. Physiol., 257, R300-R305 (1989).

2) Gwag T., Lee K., Ju H., Shin H., Lee J. W., Choi I., Cell. Physiol. Biochem., 24, 537-546 (2009).

3) Chan K. M., Decker E. A., Crit. Rev. Food Sci. Nutr., 34, 403-426 (1994).

4) Davies K. J., Quintanilha A. T., Brooks G. A., Packer L., Biochem. Biophys. Res. Commun., 107, 1198-1205 (1982).

5) Walker P. M., Ann. Vasc. Surg., 5, 399-402 (1991).

6) Nishida H., Ichikawa H., Konishi T., J. Pharmacol. Sci., 105, 342352 (2007).

7) Qu-Petersen Z., Deasy B., Jankowski R., Ikezawa M., Cummins J., Pruchnic R., Mytinger J., Cao B., Gates C., Wernig A., Huard J., J. Cell Biol., 157, 851-864 (2002).

8) Huard J., Cao B., Qu-Petersen Z., Birth Defects Res. C. Embryo Today, 69, 230-237 (2003).

9) Morimoto R. I., Sarge K. D., Abravaya K., J. Biol. Chem., 267, 21987-21990 (1993)

10) Li C. Y., Lee J. S., Ko Y. G., Kim J. I., Seo J. S., J. Biol. Chem., 275, $25665-25671$ (2000).

11) Mailhos C., Howard M. K., Latchman D. S., Neuroscience, 55, 621627 (1993).

12) Jäättelä M., Wissing D., Bauer P. A., Li G. C., EMBO J., 11, $3507-$ 3512 (1992).

13) Simon M. M., Krone C., Schwarz A., Luger T. A., Jäättelä M., Schwarz T. J., Clin. Invest., 95, 926-933 (1995).

14) Samali A., Cotter T. G., Exp. Cell Res., 223, 163-170 (1996).

15) Senf S. M., Dodd S. L., McClung J. M., Judge A. R., FASEB J., 22, $3836-3845$ (2008).
16) Thompson C. B., Science, 267, 1456-1462 (1995).

17) Price D. L., Sisodia S. S., Borchelt D. R., Science, 282, 1079-1083 (1998).

18) Martin S. J., Newmeyer D. D., Mathias S., Farschon D. M., Wang H. G., Reed J. C., Kolesnick R. N., Green D. R., EMBO J., 14, 51915200 (1995).

19) Buzzard K. A, Giaccia A. J., Killender M., Anderson R. L., J. Biol. Chem., 273, 17147-17153 (1998).

20) Kim S. H., Sung S. H., Choi S. Y., Chung Y. K., Kim J., Kim Y. C., Org. Lett., 7, 3275-3277 (2005).

21) Ahn S. I., Park S. K., Lee M. Y., Youn H. S., Mol. Cell. Toxicol., 5, $141-146$ (2009).

22) Jackson M. J., O’Farrell S., Br. Med. Bull., 49, 630-641 (1993).

23) Rodriguez M. C., Free Radic. Biol. Med., 34, 1217-1220 (2003).

24) Wang N. L., Liou Y. L., Lin M. T., Lin C. L., Chang C. K., J. Pharmacol. Sci., 97, 253-265 (2005).

25) Haycock J. W., MacNeil S., Mantle D., Neuroreport, 9, 2201-2207 (1998).

26) Haycock J. W., MacNeil S., Jones P., Harris J. B., Mantle D., Neuroreport, 8, 357-361 (1996).

27) Ahn J. H., Ko Y. G., Park W. Y., Kang Y. S., Chung H. Y., Seo J. S., Mol. Cells, 9, 200-206 (1999).

28) Mosser D. D., Caron A. W., Bourget L., Denis-Larose C., Massie B. Mol. Cell. Biol., 17, 5317-5327 (1997).

29) Jäättelä M., Wissing D., Kokholm K., Kallunki T., Egeblad M., EMBO J., 17, 6124-6134 (1998).

30) Gabai V. L., Meriin A. B., Mosser D. D., Caron A. W., Rits S., Shifrin V. I., Sherman M. Y., J. Biol. Chem., 272, 18033-18037 (1997).

31) Meriin A. B., Gabai V. L., Yaglom J., Shifrin V. I., Sherman M. Y. J. Biol. Chem., 273, 6373-6379 (1998). 